\title{
National Survey of Emergency Physicians to Define Functional Decline in Elderly Patients with Minor Trauma
}

\author{
Kasim Abdulaziz, $\mathrm{MSc}^{*{ }^{\dagger}}$; Jamie Brehaut, $\mathrm{PhD}^{*{ }^{\dagger}}$; Monica Taljaard, $\mathrm{PhD}^{*{ }^{\dagger}}$; Marcel Émond, $\mathrm{MSc}^{\ddagger \S}$; \\ Marie-Josée Sirois ${ }^{\delta \uparrow}$; Jacques S. Lee, MD, MSc"; Laura Wilding, RN,MHS**; Jeffrey J. Perry, MD, MSc* ${ }^{*^{*} *}$
}

\section{ABSTRACT}

Background: There are a number of screening tools to predict return to the emergency department (ED) in elderly trauma patients, but none exist to specifically screen for functional decline after a minor injury. The objective of this study was to identify outcome measures for a possible future clinical decision rule to be used in the ED to identify previously independent patients at high risk of functional decline at six months post minor injury.

Methods: After a rigorous development process, a survey instrument was administered to a random sample of 178 emergency physicians using the Dillman's Tailored Design Method.

Results: Of 156 eligible surveys, we received 81 completed surveys (response rate $51.9 \%$ ). Considering all 14 activities of daily living ( $A D L$ ) items, $90 \%$ of physicians deemed a minimal clinically important difference (MCID) in function to be at least three points on the 28-point Older Americans Resources and Services (OARS) ADL Scale as clinically significant. A tool with a sensitivity of $93 \%$ to detect patients at risk of functional decline at six months post injury would meet or exceed the sensitivity deemed to be required by $90 \%$ of physicians. The majority of emergency physicians do not assess elderly injured patients for the majority of the tasks.

Conclusions: A drop of three points on the 28-point OARS ADL Scale would be deemed clinically important by the vast majority of emergency physicians. Further, a sensitivity of 93\% for a clinical decision tool would satisfy the MCID requirements of the vast majority of emergency physicians. There appears to be a gap between physician knowledge and actual practice. We intend to use these findings in the development of a clinical decision rule to identify high-risk elderly trauma patients.

\section{RÉSUMÉ}

Contexte: II existe un certain nombre d'outils de dépistage permettant de prévoir le retour au service des urgences de patients âgés ayant subi un trauma, mais il n'en existe aucun qui porte tout particulièrement sur la diminution de la capacité fonctionnelle après une blessure légère. L'étude visait donc à dégager des critères d'évaluation en vue d'établir une future règle de prise de décision clinique, applicable au service des urgences (SU), permettant de cerner des patients antérieurement autonomes, fortement prédisposés à une diminution de la capacité fonctionnelle, 6 mois après une blessure légère.

Méthode: Après un processus rigoureux d'élaboration, un questionnaire d'enquête a été envoyé à un échantillon aléatoire de 178 médecins d'urgence, selon une version modifiée de la méthode de conception sur mesure de la Dillman.

Résultats: Sur une possibilité de 156 médecins jugés admissibles à l'étude, 81 ont répondu au questionnaire (taux de réponse: $51,9 \%$ ). Compte tenu des 14 éléments constituant les activités de la vie quotidienne (AVQ), $90 \%$ des médecins considéraient que, pour être significatif sur le plan clinique, l'écart minimal d'importance clinique, relatif à la capacité fonctionnelle, devait être d'au moins 3 points sur I'échelle Older Americans Resources and Services (OARS) des AVQ, qui compte 28 points. De plus, un outil ayant une sensibilité de détection de $93 \%$ des patients prédisposés à une diminution de la capacité fonctionnelle, 6 mois après une blessure, atteindrait et dépasserait même le seuil de sensibilité jugé nécessaire par $90 \%$ des médecins. Toutefois, la majorité des médecins d'urgence n'évalue pas la capacité des personnes âgées, blessées à réaliser la plupart des tâches.

Conclusions: Une perte de 3 points sur un total de 28, sur l'échelle OARS des AVQ serait considérée comme importante sur le plan clinique par la grande majorité des médecins

From the *Department of Epidemiology and Community Medicine, University of Ottawa, Ottawa, ON; †Clinical Epidemiology Program, Ottawa Hospital Research Institute, Ottawa, ON; ‡Department of Family and Emergency Medicine, Université Laval, Laval, QC; §Unité de recherche en traumatologie-urgence-soins intensifs du Centre de recherche FRO-S du CHA de Québec, Laval, QC; qDépartement de réadaptation, Université Laval, Laval, QC; ॥Clinical Epidemiology Unit, Department of Emergency Medicine, University of Toronto, Sunnybrook Health Sciences Center, Toronto, ON; and ${ }^{*}$ Department of Emergency Medicine, University of Ottawa, Ottawa, ON.

Correspondence to: Dr. Jeffrey J. Perry, Epidemiology Program, F6, The Ottawa Hospital, Civic Campus, 1053 Carling Avenue, Ottawa, ON, K1Y 4E9; Email jperry@ohri.ca 
d'urgence. De plus, une sensibilité de détection de $93 \%$ pour un outil de prise de décision clinique répondrait aux exigences de la grande majorité des médecins d'urgence. II semble toutefois y avoir un écart entre les connaissances des médecins et la pratique. Les auteurs entendent utiliser les résultats de l'étude dans l'élaboration d'une règle de prise de décision clinique permettant de cerner les patients âgés, blessés, fortement prédisposés à une diminution de la capacité fonctionnelle.

Keywords: Functional Decline, Elderly, Emergency Department, Geriatric Assessment, Activities of Daily Living (ADL), Older Americans Resources and Services (OARS), Minor Injuries

\section{INTRODUCTION}

The proportion of Canadians 65 years of age or older is expected to increase from $14.4 \%$, in 2011 , to one in every four persons by $2051 .^{1,2}$ A substantial number of elderly patients sustain injuries and seek treatment in the emergency department (ED). ${ }^{3}$ In 2011, almost half a million injured elderly patients were treated in Canadian EDs. ${ }^{4}$

The fast-paced and frequently overcrowded nature of the ED environment can prevent physicians from assessing elderly trauma patients for current and future functional decline. Some $75 \%$ of elderly patients with injuries are discharged home after their ED visit, often without an assessment for functional independence. ${ }^{3,5}$ Approximately $10 \%-45 \%$ of the patients will develop a decline in function that persists up to seven months post injury. ${ }^{3-13}$ Functional decline, or the reduction in ability to perform self-care activities of daily living (ADL) because of a decrement in physical functioning, ${ }^{14-17}$ is a common and serious problem in elderly patients. ${ }^{16,17}$ Functional decline is associated with social isolation, reduced quality of life, and death. ${ }^{3,5,7,8,14,18-22}$ It is also an important predictor of hospitalization, ${ }^{23,24}$ prolonged hospital stay, ${ }^{25}$ repeat $\mathrm{ED}$ visits, ${ }^{7,26}$ and the need for home care ${ }^{25}$. Moreover, functional decline is the most important predictor of admission to institutions and of disproportionate use of health services by the elderly population. ${ }^{16,17,25-27}$ It has been suggested that identification of functional decline in elderly patients is more predictive of mortality than organ damage or severity of illness. ${ }^{28,29}$

A number of assessment scales to measure functional independence in the elderly exist, the most noteworthy of which is the Older Americans Resources and Services (OARS) ADL Scale, but such scales should not be confused with screening tools purposefully designed to identify patients at risk of functional decline. The OARS Scale is a 14-item questionnaire involving seven basic and seven instrumental activities of daily living (ADL/IADL) items. ${ }^{30-33}$ Each of the 14 items rates the patients on their ability to perform the activities independently. The items in the OARS ADL Scale are graded on a three-point scale as follows: 0 (completely unable to perform the activity), 1 (can perform the activity but with some help), and 2 (can perform the activity without any help). Scores range from 0 to 28 , with the highest score indicating complete independence in performing the activities of daily living and the lowest score indicating that the patient is unable to perform the activities at all. ${ }^{30,34}$ The OARS ADL scale has been validated for ED patients and has been successfully used in ED studies for both in-person and over the telephone interviews. ${ }^{32,35}$

There are a number of screening tools for return to the ED, but none exist to specifically screen for functional decline after a minor injury. Our goals were to determine what emergency physicians deem to be a minimal clinically important difference on the 28-point OARS ADL Scale, and what the required sensitivity would be for a clinical decision tool to identify elderly patients at high risk of functional decline six months after sustaining a minor trauma. Although we do not plan to use the OARS after this study, we chose to use it to plan the development of a screening tool or clinical decision rule to identify previously independent elderly patients at high risk of functional decline.

\section{METHODS}

\section{Study design and participants}

This study involved a postal survey of emergency physicians across Canada. To be eligible for study participation, physicians had to have been currently practicing emergency medicine that included care delivery to patients 65 years and older. A random sample of 178 emergency physicians was selected from the Canadian Medical Directory (total population selected from: 2,450 registered as of August 23, 2011). A $\$ 10$ coffee card was given with the first survey to a random selection of $50 \%$ of those invited to participate. 
Dillman's Tailored Design Method was followed. ${ }^{14}$ Key informant interviews (pre-surveying) were conducted to establish survey feasibility, obtain current knowledge on functional decline, and determine ideal methods of gathering information on sensitivity and minimal point drop on the OARS ADL Scale. Cognitive interviews were conducted to evaluate the clarity, comprehensibility, and face validity of the draft survey instrument. Finally, a pilot survey was conducted to pinpoint and fix any problems with the final draft of the survey instrument and its implementation procedures.

\section{Outcome measures}

The primary objectives of this study were to determine: 1) the minimal clinically important difference (MCID) or point drop in basic ADL and IADL scores as defined by emergency physicians; and 2) the sensitivity required by emergency physicians for a clinical tool to screen for functional decline at six months post injury. For the primary objectives, we were interested in determining those values that the vast majority (defined as $90 \%$ or more) of physicians would be satisfied with (i.e., the 10th percentile for the point drop and the 90th percentile for the sensitivity). This study also investigated emergency physicians' current knowledge and practice patterns on assessment of functional decline.

Functional decline is often defined and measured by a reduction in ability to perform activities of daily living (ADL). ${ }^{25,36} \mathrm{ADL}$ have been classified into: 1) basic activities of daily living (basic ADL), including transferring, toileting, grooming, dressing, bathing and feeding oneself; and 2) instrumental activities of daily living (IADL) that allow an individual to live independently in a community (e.g., operate a telephone). ${ }^{37}$

\section{Questionnaire development}

To aid in the development of the survey instrument, we conducted key informant and cognitive interviews on convenience samples of emergency physicians. From the interviews, we collected a range of responses on current knowledge of functional decline in elderly patients and how it is assessed and measured. The cognitive interviews enabled us to evaluate and address any shortcomings with the questionnaire. The key informant and cognitive interviews helped guide the development of a tailored survey instrument. We pre-tested the questionnaire using a convenience sample of six local emergency physicians to identify and address any shortcomings with the instrument or the survey process.

The final questionnaire consisted of five sections with a total of 13 questions: one eligibility question, seven demographic and practice setting questions, three assessment and measurement of functional decline questions, one relevance of $\mathrm{ADL}$ items to functional decline question, and a question on the required sensitivity for the clinical decision rule. The survey material (final questionnaire, pre-notification letters, and cover letters) were translated by an official medical translator into French for physicians identified as French-speaking by the language of correspondence indicator in the Canadian Medical Directory. ${ }^{38}$

\section{Survey administration}

After finalizing the questionnaire, we mailed the surveys to 178 English- and French-speaking emergency physicians. The survey packages consisted of a cover letter, a questionnaire, and a prepaid business reply mail envelope. A week after the pre-notification letter, the first survey questionnaire, along with the coffee card, if applicable, was mailed. A reminder with a questionnaire was mailed to the non-respondents every three weeks. The final reminder was mailed using Canada Post's Xpresspost ${ }^{\mathrm{TM}}$ courier service.

The researchers coordinating this study were located at the Ottawa Hospital Research Institute in Ottawa, Ontario, Canada. This study was approved by the Ottawa Health Science Network Research Ethics Board.

\section{Data analysis}

Descriptive statistics were calculated. The four possible physician responses on the assessment of functional decline ("always," "often," "rarely," and "never") were dichotomized as assess ("always" or "often") or do not assess ("rarely" or "never"). The four possible responses on the importance of the basic ADL and IADL items related to functional decline ("very important," "somewhat important," "less important," and "not important") were dichotomized as important ("very important" or "somewhat important") or not ("less important" or "not important"). Gaps between physician knowledge and actual practice were illustrated with bar graphs. The minimal clinically important difference in the OARS ADL score and required sensitivities were presented using frequency distributions and boxplots. 
To evaluate the potential for non-response bias, characteristics of respondents and non-respondents were compared using chi-squared tests. Two-sided significance tests were conducted at an alpha level of 0.05 . The sample size was calculated to yield a two-sided 95\% confidence interval around the mean estimated sensitivity with a maximum width of $4 \%$, accounting for the finite population correction factor and an anticipated response rate of $55 \%$. We estimated the standard deviation as the range divided by four, based on the well-known property of the normal distribution that approximately $95 \%$ of responses are within plus or minus two standard deviations of the mean. We anticipated the range of responses as being between $60 \%$ and $100 \%$, and so we obtained a standard deviation of $10 \%$. Data were analyzed using SAS version 9.2 (SAS Institute, Cary, NC).

\section{RESULTS}

\section{Respondents}

Of 178 emergency physicians invited to participate, seven were unreachable because they had moved, and 15 were ineligible, as they were no longer practicing or were not seeing elderly patients. We received $81 \mathrm{com}-$ pleted surveys (including five from the local pilot survey) from a total of 156 eligible physicians, resulting in a response rate of $51.9 \%$. The response rate of the physicians who received an incentive $(56.8 \%)$ was higher than the response rate of physicians who did not receive an incentive $(46.7 \% ; p=0.2061)$. The five pilot surveys were included in the analyses, as the pilot and final questionnaire were not substantially different.

Demographic characteristics of the participants is provided in Table 1. A higher proportion of participants were male $(75.3 \%)$, the most common practice location was a teaching hospital (44.4\%), and over $69.0 \%$ had been in practice for 10 or more years.

To test for non-response bias, we studied two demographic variables that were available on the sampling frame: language of correspondence and geographic region of residence (Table 2). There was no indication of non-response bias in terms of the language of the questionnaire, as indicated by the non-significant differences $(p=0.846)$ in response rates among the English- and French-speaking emergency physicians. Similarly, there was no indication of a significant difference in response rates $(p=0.236)$ when we compared the regions.

\begin{tabular}{|c|c|}
\hline Characteristic & $\begin{array}{l}\mathrm{n}(\%) \text { of Respondents } \\
(\mathrm{N}=81)\end{array}$ \\
\hline \multicolumn{2}{|l|}{ Gender } \\
\hline Male & $61(75.3)$ \\
\hline Female & $20(24.7)$ \\
\hline \multicolumn{2}{|l|}{ Age } \\
\hline$<35$ & $11(13.6)$ \\
\hline $35-44$ & $12(14.8)$ \\
\hline $45-54$ & $36(44.4)$ \\
\hline$\geq 55$ & $21(25.9)$ \\
\hline Missing & $1(0.0)$ \\
\hline \multicolumn{2}{|l|}{ Years in Practice } \\
\hline$<10$ & $25(30.9)$ \\
\hline $10-19$ & $33(40.7)$ \\
\hline$\geq 20$ & $23(28.4)$ \\
\hline \multicolumn{2}{|l|}{ Years Residency Training } \\
\hline$<3$ & $17(21.0)$ \\
\hline $3-5$ & $60(74.1)$ \\
\hline$>5-9$ & $3(3.7)$ \\
\hline$\geq 10$ & $0(0.0)$ \\
\hline Missing & $1(0.0)$ \\
\hline \multicolumn{2}{|l|}{ Practice Setting } \\
\hline Teaching Hospital & $36(44.4)$ \\
\hline $\mathrm{CDGH}^{*}$ : Teaching & $31(38.3)$ \\
\hline CDGH: Non-Teaching & $13(16.0)$ \\
\hline Other & $1(1.2)$ \\
\hline \multicolumn{2}{|c|}{ Number of Patients Seen/Week } \\
\hline$\leq 28$ & $3(3.7)$ \\
\hline $29-60$ & $19(23.5)$ \\
\hline $61-100$ & $36(44.4)$ \\
\hline$>100$ & $23(28.4)$ \\
\hline \multicolumn{2}{|c|}{ Number of Elderly Patients Seen/Week } \\
\hline$\leq 20$ & $16(19.8)$ \\
\hline $21-30$ & $18(22.2)$ \\
\hline $31-50$ & $31(38.3)$ \\
\hline$>50$ & $15(18.5)$ \\
\hline Missing & $1(0.0)$ \\
\hline
\end{tabular}

\section{$M C I D$ and required sensitivity}

In all, $90 \%$ of participants deemed a three or more point drop on the 28-point OARS ADL Scale, when the patient does not have support at home, and a five or more point drop when the patient has support at home, to be a clinically significant change in functional decline when considering all the 14 basic ADL and IADL items (Table 3). When only the seven basic ADL items were considered, $90 \%$ of participants considered a one or more point drop when the patient does not have support at 
Functional decline in elderly patients with minor trauma

\begin{tabular}{|c|c|c|c|}
\hline Characteristic & Respondents (n) \% & Non-respondents (n) \% & $p$ value \\
\hline Language of the Questionnaire & & & 0.846 \\
\hline English & $70(86.4)$ & $64(85.3)$ & \\
\hline French & $11(13.6)$ & $11(14.7)$ & \\
\hline Region & & & 0.236 \\
\hline Western Canada* & $23(28.4)$ & $30(40.0)$ & \\
\hline Ontario & $38(46.9)$ & $28(37.3)$ & \\
\hline Quebec & $14(17.3)$ & $15(20.0)$ & \\
\hline Eastern Canada** & $6(7.4)$ & $2(2.7)$ & \\
\hline
\end{tabular}

\begin{tabular}{l}
$\begin{array}{l}\text { Table 3. Required point drop to imply functional decline and } \\
\text { required sensitivity for a clinical decision rule that would meet } \\
\text { or exceed expectations for } \mathbf{9 0 \%} \text { of participants }\end{array}$ \\
$\begin{array}{l}\text { Point Drop } \\
\text { or Sensitivity }\end{array}$ \\
\hline $\begin{array}{l}\text { Minimum Point Drop in All 14 Basic } \\
\text { ADL/IADL Items* }\end{array}$ \\
$\begin{array}{l}\text { If patient has NO support at home } \\
\text { If patient has support at home }\end{array}$ \\
$\begin{array}{l}\text { Minimum Point Drop in the 7 ADL Items* } \\
\text { If patient has NO support at home }\end{array}$ \\
If patient has support at home \\
Sensitivity* \% \\
\hline *Meet or exceed expectations for $90 \%$ of participants \\
\hline
\end{tabular}

home, and a two or more point drop when the patient has support at home, to be clinically significant. Finally, $90 \%$ of emergency physicians would be satisfied with a sensitivity of $93 \%$ for a clinical decision rule to identify elderly patients at high risk of functional decline.

The distribution of physician responses, to determine a clinically significant point drop, as well as the required sensitivity, is graphically presented in Figures 1 and 2 . In general we found a small variability among the emergency physicians on the required sensitivity and the clinically significant point drop to define functional decline. There was, however, a notable variability among the physicians regarding the point drop deemed to be clinically significant when considering all $14 \mathrm{ADL}$ items in a patient with support at home.

\section{Assessment for and relevance of ADL to functional decline}

Figure 3 provides physician attitudes on the assessment and importance of activities of daily living on functional

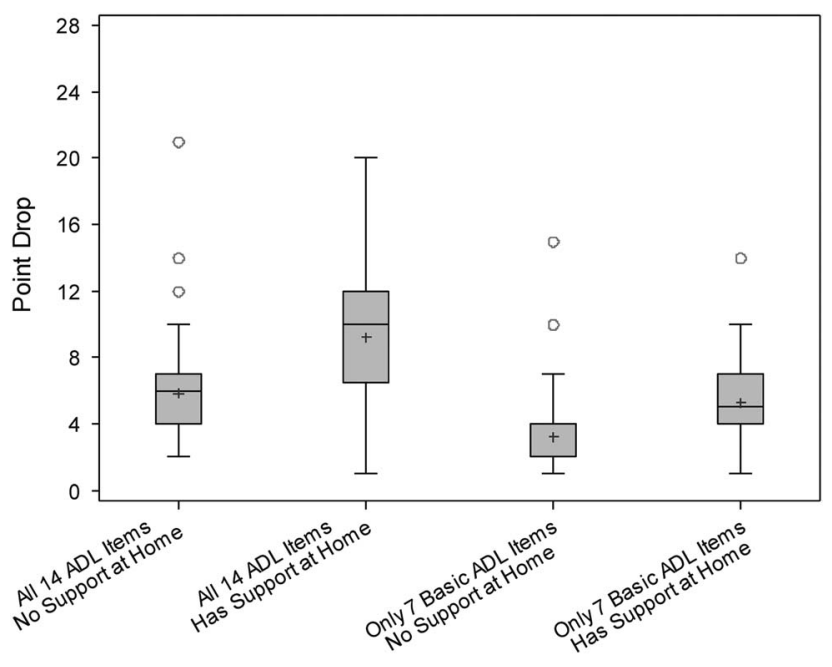

Figure 1. Boxplots Showing Distribution of Emergency Physician Responses Regarding a Clinically Significant Point Drop Deemed to Imply Functional Decline

decline. This illustrates that most emergency physicians do not assess elderly injured patients for the majority of the tasks, even when the tasks are felt to be important.

\section{DISCUSSION}

With an increasing geriatric population and concomitant burden on EDs, it is essential to develop clinically useful tools to improve ED efficiency. One example would be a tool to identify elderly patients at high risk of functional decline following a minor injury. Screening tools, such as the Hospital Admission Risk Profile (HARP), Identification of Seniors at Risk (ISAR), Triage Risk Screening Tool (TRST), and Score Hospitalier d'Evaluation du Risque de Perte d'Autonomie (SHERPA) exist to screen for functional 
decline, but are not specific for functional decline in elderly patients after minor injuries. ${ }^{16,17,25,26} \mathrm{We}$ conducted this study of emergency physicians to define

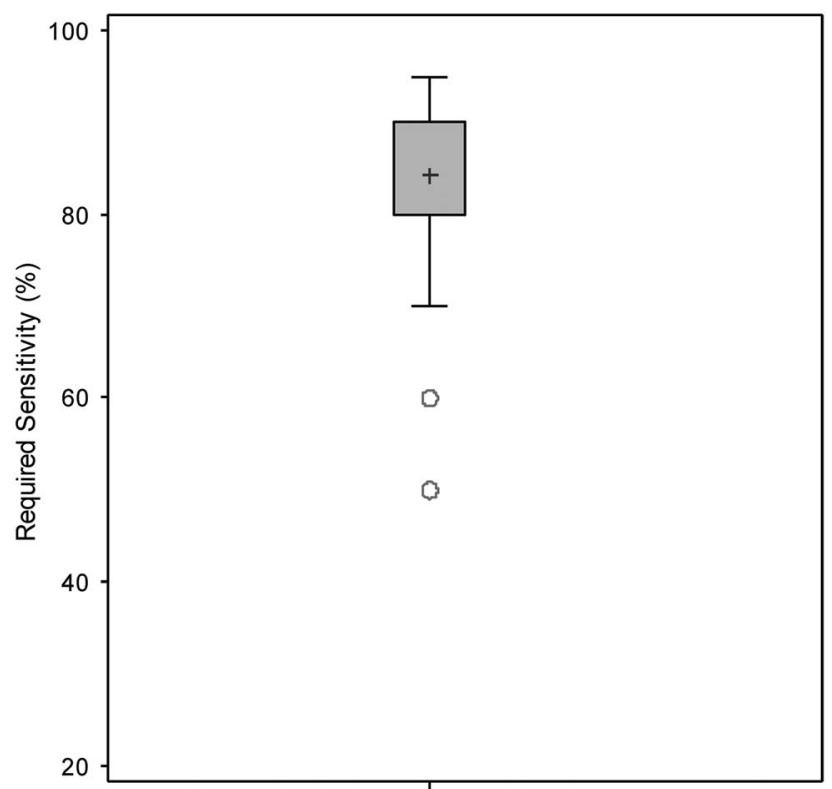

Figure 2. Boxplot Showing Distribution of Emergency Physician Responses for the Required Sensitivity of a Clinical Tool what constitutes a clinically significant functional decline six months after sustaining a minor trauma.

\section{MCID and required sensitivity}

We found that $90 \%$ of emergency physicians deemed a drop in function of at least three points (i.e., the MCID) on the 28-point OARS ADL Scale as clinically significant when considering all 14 basic ADL and IADL items. When only the seven basic ADL items are considered, $90 \%$ of emergency physicians deemed a drop in function of one or more points to be clinically significant. Physicians were asked for their opinions on the point drop based on whether the patient had support at home or not, since a number of physicians in our key informant interviews had raised the issue and suggested we ask the questions separately. We found that a tool to detect previously independent patients at risk of a functional decline at six months post injury would require a sensitivity of $93 \%$ to meet or exceed requirements for $90 \%$ of emergency physicians. We opted to consider the 90th percentile more important than the mean or the median, because we would desire that a vast majority of physicians be satisfied with the outcome measures; medians would satisfy only half of the physicians.

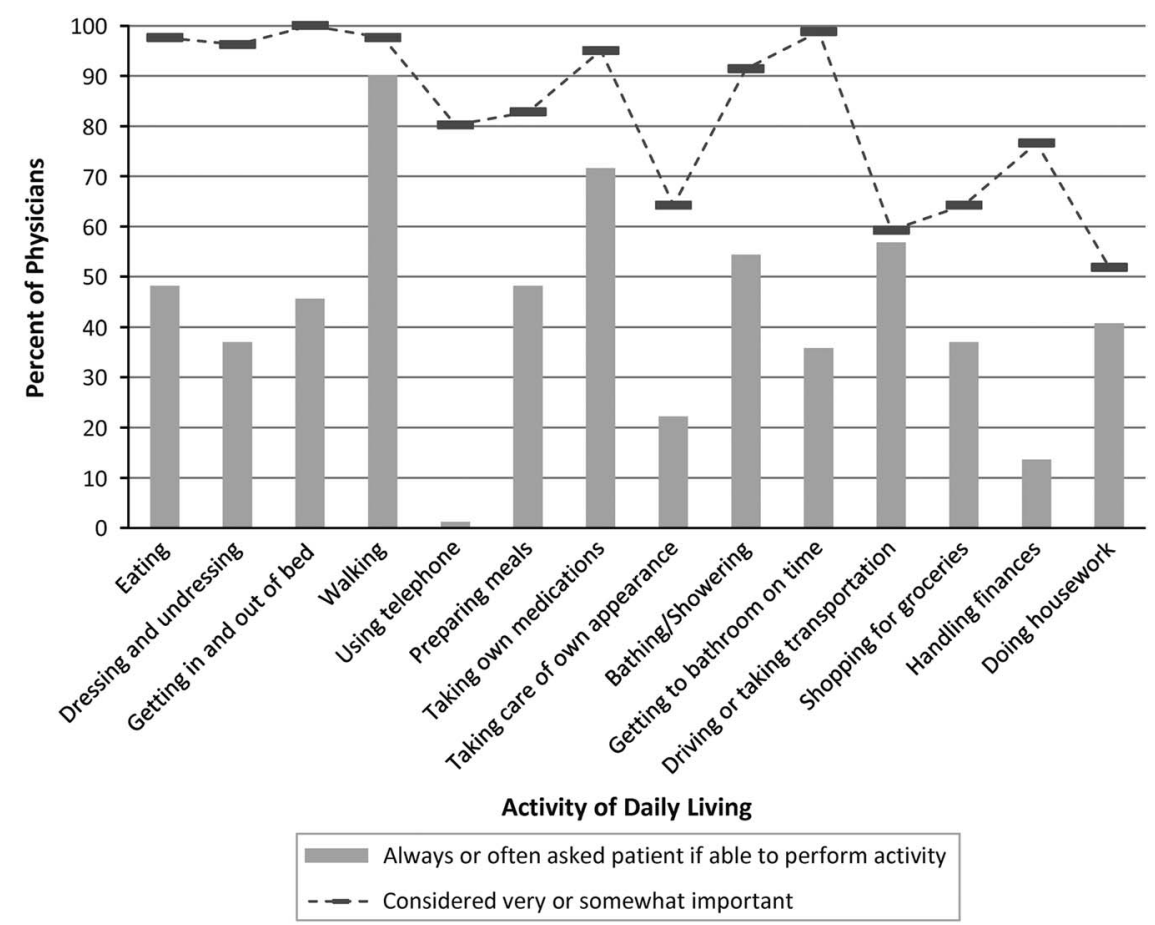

Figure 3. Percent of Emergency Physicians who Perceive Activity of Daily Living to be Very or Somewhat Important in Terms of Performance by Patients (dashed lines) and Percent of Emergency Physicians Always or Often Asking if Patients Have Difficulty Performing Activity of Daily Living (solid bars). 
In our study, only $25 \%$ of the physicians had indicated they would accept a sensitivity of up to $80 \%$. Despite the fact that the most commonly used tool (ISAR) has a sensitivity of $81 \%,{ }^{30,34} 90 \%$ of our study participants indicated that they would require a more sensitive tool. Our results suggest that this tool is not sensitive enough to be acceptable for $75 \%$ of our respondents (i.e., the percent of our respondents requiring a sensitivity of greater than $81 \%$, which is the sensitivity of the ISAR).

Our results suggest that the basic ADL items are weighted more by emergency physicians than the IADL items. The importance of the basic ADL items to functional decline is shown by the participants' responses of a smaller clinically significant point drop in the basic ADL compared to the combined basic ADL and IADL items. As the OARS ADL Scale uses a combined score (basic ADL + IADL) with no weights given to the items, caution should be exercised when using the overall OARS ADL Scale. These findings on the importance of the basic ADL items over the IADL items should be considered when determining the outcome measure of a clinical tool for identifying elderly patients at high risk of functional decline after a minor injury.

\section{Assessment and relevance of ADL to functional decline}

A high proportion of emergency physicians do not assess the patients on all the basic ADL and IADL items, despite their opinions on the high importance of the tasks to functional decline. ${ }^{3,39,40}$ A number of reasons may exist for this gap between knowledge and actual practice. As reported by previous studies, emergency physicians almost always face time pressures to treat patients, due to a high patient volume, and typically do not have the luxury of time to assess for functional decline., 39,40 Under-assessment of this nature can become especially problematic when the injuries of the elderly patients are not apparent at the time of ED visit, potentially leading to functional decline weeks and months later. For example, soft tissue injuries, such as sprains and contusions, are often less apparent on an initial assessment, and may be overlooked by emergency physicians with regards to functional decline. Our findings suggest that emergency physicians are aware of the importance of the basic ADL and IADL items in terms of functional performance by elderly patients, but do not routinely assess them. A clinical decision rule that identified patients at high risk of functional decline following a minor injury could help close the gap between physician knowledge and actual clinical practice pattern.

\section{Respondents}

Our response rate of $51.9 \%$ is consistent with research suggesting that response rates of between $34 \%$ and $70 \%$ are typical for physician surveys. ${ }^{41-43}$ It is also close to the mean response rate of $54 \%$ reported by a systematic review of physician postal surveys. ${ }^{32,35}$ Our rigorous methodological approach, including key informant interviews, cognitive interviews, pilottesting, short and concise questionnaires with incentives to half of the physicians, and a special contact, optimized our response rate and yielded very few missing data.

The distribution of the respondent characteristics was not surprising. The higher proportion of male participants is consistent with the gender distribution of the population of practicing Canadian physicians in Canada. ${ }^{44}$ Further, our data did not suggest any evidence of non-response bias, although this still cannot be entirely ruled out.

\section{LIMITATIONS}

This study has a number of limitations that should be considered. We found a small number of physicians who had retired or moved who were still in the Canadian Medical Directory. It is possible that the directory was missing some physicians, potentially leading to enrollment bias. We feel that any such limitations are minimal, as the Canadian Medical Directory claims to be at least $97 \%$ accurate, and was the best physician directory we could identify and utilize. ${ }^{38}$ Measurement error regarding the point drop value is possible, as it is likely participants envisioned different injuries and scenarios when providing their opinions on the point drops.

Another potential limitation of this study is that the OARS ADL Scale we used does not weight the ADL items, in contrast to other assessment instruments where weights apply to different ADL items. However, the OARS ADL Scale has been validated in the ED, and is anticipated to be used in the ED, and so we elected to use this tool in our study.

Finally, as this study was a self-administered postal survey, it was potentially susceptible to "social desirability bias," in that physicians might have responded 
based on an ideal practice scenario rather than their actual practice or attitudes.

\section{CONCLUSION}

Our results indicate that a minimal clinically important difference in function-one that would satisfy $90 \%$ of emergency physicians-is three points on the 28-point OARS ADL Scale. When considering only the seven basic ADL items, the minimal clinically important difference is one point. Moreover, a sensitivity of $93 \%$ would meet or exceed $90 \%$ of emergency physicians' requirements for any clinical tool to identify injured seniors at high risk of functional decline six months post injury. We anticipate that these findings will help our study group identify clinically relevant outcomes for a future clinical decision rule, in contrast (for example) to what the general population might perceive as an appropriate outcome.

Currently, a high proportion of emergency physicians indicate that they do not assess patients for functional decline. Such an under-assessment may lead to severe health outcomes, including functional decline at six months post minor injury. We feel that increasing physician awareness of the potential seriousness of apparently "minor injuries" in otherwise independent seniors is important. Development of a clinical decision tool may help emergency physicians identify elderly patients at high risk of functional decline, and our plan is for the results of this survey to inform the development of such a rule. A validated clinical decision rule could help emergency physicians take appropriate steps, such as referring the patient to a geriatric assessment clinic, to prevent functional decline from even occurring in high-risk elderly trauma patients.

Competing Interests: Funding by Canadian Institutes of Health Research (CIHR) for the Canadian Emergency Department Team Initiative (CETI) in Mobility in Aging (Grant \# AAM-108750) and the University of Ottawa Department of Emergency Medicine.

\section{REFERENCES}

1. Statistics. Canada. Canadian population in 2011. Population by sex and age group; 2011. Available at: http://www12.statcan.gc. $\mathrm{ca} /$ census-recensement/2011/as-sa/98-311-x/98-311-x2011001eng.pdf

2. Human Resources and Skills Development Canada. Canadians in Context - Aging Population. Human Resources and Skills Development Canada; 2011.
3. Wilber ST, Blanda M, Gerson LW, et al. Short-term functional decline and service use in older emergency department patients with blunt injuries. Acad Emerg Med 2010;17(7):679-86.

4. Sirois MJ, Emond M, Ouellet MC, et al. Cumulative incidence of functional decline after minor injuries in previously independent older Canadian individuals in the emergency department. 7 Am Geriatr Soc 2013;61(10):1661-8.

5. Salvi F, Morichi V, Grilli A, et al. The elderly in the emergency department: a critical review of problems and solutions. Intern Emerg Med 2007;2(4):292-301.

6. Grisso JA, Schwarz DF, Wolfson V, et al. The impact of falls in an inner-city elderly African-American population. 7 Am Geriatr Soc 1992;40(7):673-8.

7. Rowland K, Maitra AK, Richardson DA, et al. The discharge of elderly patients from an accident and emergency department: functional changes and risk of readmission. Age \& Ageing 1990;19(6):415-8.

8. Currie CT, Lawson PM, Robertson CE, et al. Elderly patients discharged from an accident and emergency department-their dependency and support. Arch Emerg Med 1984;1(4):205-13.

9. Victor CR, Vetter NJ. Measuring outcome after discharge from hospital for the elderly-a conceptual and empirical investigation. Arch Gerontol Geriatr 1989;8(1):87-94.

10. Shapiro MJ, Partridge RA, Jenouri I, et al. Functional decline in independent elders after minor traumatic injury. Acad Emerg Med 2001;8(1):78-81.

11. Ferrera PC, Bartfield JM, D'Andrea CC. Geriatric trauma: outcomes of elderly patients discharged from the ED. Am 7 Emerg Med 1999;17(7):629-32.

12. Russell MA, Hill KD, Blackberry I, et al. Falls risk and functional decline in older fallers discharged directly from emergency departments. 7 Gerontol A Biol Sci Med Sci 2006;61(10):1090-5.

13. Carpenter CR. Deteriorating functional status in older adults after emergency department evaluation of minor trauma-opportunities and pragmatic challenges. $7 \mathrm{Am}$ Geriatr Soc 2013;61(10):1806-7.

14. Sutton M, Grimmer-Somers K, Jeffries L. Screening tools to identify hospitalised elderly patients at risk of functional decline: a systematic review. Int 7 Clin Pract 2008;62 (12):1900-9.

15. Inouye SK, Bogardus ST Jr., Baker DI, et al. The Hospital Elder Life Program: a model of care to prevent cognitive and functional decline in older hospitalized patients. Hospital Elder Life Program. 7 Am Geriatr Soc 2000; 48(12):1697-706.

16. Hebert R. Functional decline in old age. CMA7 1997; 157(8):1037-45.

17. Hoogerduijn JG, Schuurmans MJ, Duijnstee MS, et al. A systematic review of predictors and screening instruments to identify older hospitalized patients at risk for functional decline. 7 Clin Nurs 2007;16(1):46-57.

18. Moritz DJ, Kasl SV, Berkman LF. Cognitive functioning and the incidence of limitations in activities of daily living in an elderly community sample. Am 7 Epidemiol 1995;141(1):41-9.

19. Winograd CH, Gerety MB, Chung M, et al. Screening for frailty: criteria and predictors of outcomes. 7 Am Geriatr Soc 1991;39(8):778-84. 
20. Narain P, Rubenstein LZ, Wieland GD, et al. Predictors of immediate and 6-month outcomes in hospitalized elderly patients. The importance of functional status. $7 \mathrm{Am}$ Geriatr Soc 1988;36(9):775-83.

21. Asakawa T, Koyano W, Ando T, et al. Effects of functional decline on quality of life among the Japanese elderly. Int 7 Aging Hum Dev 2000;50(4):319-28.

22. Denman SJ, Ettinger WH, Zarkin BA, et al. Short-term outcomes of elderly patients discharged from an emergency department. 7 Am Geriatr Soc 1989;37(10):937-43.

23. Boult C, Dowd B, McCaffrey D, et al. Screening elders for risk of hospital admission. I Am Geriatr Soc 1993; 41(8):811-7.

24. Caplan GA, Brown A, Croker WD, et al. Risk of admission within 4 weeks of discharge of elderly patients from the emergency department-the DEED study. Discharge of elderly from emergency department. Age Ageing 1998; 27(6):697-702.

25. Hastings SN, Heflin MT. A systematic review of interventions to improve outcomes for elders discharged from the emergency department. Acad Emerg Med 2005;12(10): 978-86.

26. Aminzadeh F, Dalziel WB. Older adults in the emergency department: a systematic review of patterns of use, adverse outcomes, and effectiveness of interventions. Ann Emerg Med 2002;39(3):238-47.

27. Rockwood K, Stolee P, McDowell I. Factors associated with institutionalization of older people in Canada: testing a multifactorial definition of frailty. 7 Am Geriatr Soc 1996; 44(5):578-82 .

28. Fried LP, Tangen CM, Walston J, et al. Frailty in older adults: evidence for a phenotype. 7 Gerontol A Biol Sci Med Sci 2001;56(3):M146-56.

29. Satish S, Winograd CH, Chavez C, et al. Geriatric targeting criteria as predictors of survival and health care utilization. 7 Am Geriatr Soc 1996;44(8):914-21.

30. Fillenbaum G. Multidimensional Functional Assessment of Older Adults: The Duke Older Americans Resources and Services Procedures. Hillsdale: Erlbaum; 1988.
31. Wilber ST, Blanda M, Gerson LW. Does functional decline prompt emergency department visits and admission in older patients? Acad Emerg Med 2006;13(6):680-2.

32. McCusker J, Bellavance F, Cardin S, et al. Validity of an activities of daily living questionnaire among older patients in the emergency department. I Clin Epidemiol 1999; 52(11):1023-30.

33. McDowell I. Measuring Health: A Guide to Rating Scales and Questionnaires, 3rd ed. New York: Oxford University Press; 2006.

34. Breithaupt K, McDowell I. Considerations for Measuring Functioning of the Elderly: IRM Dimensionality and Scaling Analysis. Health Services and Outcomes Research Methodology 2001;2(1):37-50.

35. McCusker J, Bellavance F, Cardin S, et al. Detection of older people at increased risk of adverse health outcomes after an emergency visit: the ISAR screening tool. $7 \mathrm{Am}$ Geriatr Soc 1999;47(10):1229-37.

36. Lee V, Ross B, Tracy B. Functional assessment of older adults in an emergency department. Can 7 Occup Ther 2001;68(2):121-9.

37. Dillman DA. Mail and Internet Surveys: The Tailored Design Method, 2nd ed. New York: Wiley; 2007.

38. Scott's Directories. Canadian Medical Directory 2013.

39. Nankhonya JM. Screening for social needs in accident and emergency departments. F Accid Emerg Med 1994;11(2):135-6.

40. Sanders AB, Morley JE. The older person and the emergency department. 7 Am Geriatr Soc 1993;41(8):880-2.

41. Grava-Gubins I, Scott S. Effects of various methodologic strategies. Can Fam Physician 2008;54(10):1424-30.

42. Burns KE, Duffett M, Kho ME, et al. A guide for the design and conduct of self-administered surveys of clinicians. CMA7 2008;179(3):245-52.

43. Thorpe C, Ryan B, McLean SL, et al. How to obtain excellent response rates when surveying physicians. Fam Pract 2009;26(1):65-8.

44. Canadian Medical Association. Number and percent distribution of physicians by specialty and sex 2013; 2013. Available at: http://www.cma.ca. 